\title{
EFFECT OF POCO-POCO GYMNASTIC EXERCISE ON INSULIN-LIKE GROWTH FACTOR 1 AND PHYSICAL FITNESS IN THE ELDERLY
}

\author{
Retno Setianing1), Angela BM Tulaar'), Moechsin Doewes3) \\ 1)Doctoral Program in Medicine, Universitas Sebelas Maret \\ ${ }^{2)}$ Department of Physical Medicine and Rehabilitation, \\ Faculty of Medicine, Universitas Indonesia \\ 3)Faculty of Medicine, UniversitasSebelas Maret
}

\begin{abstract}
Background: Aging is a multi-factorial irreversible process associated with significant decline in muscle mass and neuromuscular functions. One of the known methods to counteract age-related changes in muscle mass and function is physical exercise. Physical activity can help older people maintain independence, recover from illness, and reduce their risk of disease. One of the popular ethnic dances from Eastern Indonesia is Poco-poco. However, little is known about the effect of poco-poco on physical fitness. This study aimed to determine the effect of poco-poco gymnastic exercise on insulin-like growth factor 1 (IGF-1) and physical fitness in the elderly.
\end{abstract}

Subjects and Method: This was a randomized control trial study conducted in Surakarta, Central Java, from March to May 2017. A sample 30 elderly people aged 60-80 years without physical or cognitive impairments was selected for this study. This sample was divided randomly into 2 groups: (1) the experimental group received the poco-poco gymnastics and (2) the control group received cardiac exercise. The dependent variables were (1) IGF-1 and (2) physical fitness, which was measured by $\mathrm{VO} 2$ max. The independent variable was poco-poco gymnastics, which was composed of a 6 -minute walk lasting for 6 weeks. Six weeks after treatment, the IGF-1 and VO2 max data between the two groups were compared and analyzed by t-test.

Results: Before treatment, the values of IGF-1 level of the experimental group $(m e a n=71.80, \mathrm{SD}=23.58)$ was lower than the control group (mean=102.27, $\mathrm{SD}=$ 40.35) with $\mathrm{p}=0.018$. These unequal values of IGF-1 at the baseline, therefore, must be controlled for in the data analysis. After 6 weeks of treatment, IGF-1 in the experimental group (mean $=73.27, \mathrm{SD}=25.75)$ was lower than in the control group (mean $=96.47, \mathrm{SD}=36.85$ ) with $\mathrm{p}=0.055$. The increase in the value of IGF1 before and after treatment was higher in the experimental group (mean $=1.47$; $\mathrm{SD}=2.17$ ) than the control group (mean $=-5.8 ; \mathrm{SD}=-3.5$ ) with $\mathrm{p}<0.001$. The increase in the value of $\mathrm{VO} 2$ max in the experimental group (mean $=18.83, \mathrm{SD}=$ 1.11) was comparable as the control group (mean $=18.74, \mathrm{SD}=0.97$ ) with $\mathrm{p}=$ o.819.

Conclusion: Poco-poco is more effective than cardiac exercise in increasing IGF-1 level, but its effectiveness is equal as cardiac exercise in increasing VO2 max level in the elderly.

Keywords: IGF-1 level, VO2 max, physical fitness, gymnastic exercise, elderly

\section{Correspondence:}

Retno Setianing. Doctoral Program in Medicine, Universitas Sebelas Maret, Jl. Ir. Sutami No. 36 A, 57126, Surakarta, Central Java.

Email: retno_permata@yahoo.co.id. Mobile: 081252964204. 